\title{
The International Treaty on Global Warming: Is it Good or Bad for the Economy?
}

\author{
Xinyu $\mathrm{Wei}^{*}$ and Wenbin $\mathrm{Bao}^{1}$ \\ ${ }^{1}$ Nanjing University of Science \& Technology, Xiaolinwei 200, Nanjing, Jiangsu Province, China
}

\begin{abstract}
Global warming is one of the hottest topics all over the world. International authorities have worked together to negotiate the Paris Agreement on global warming. This Agreement has its supporters and critics. The key question is whether on balance is the Paris Assignment good or bad for the United States economy. This paper begins with some background information leading up to the passage of the treaty. Next, I outline what is in treaty. I then critically analyze the arguments in support of and against the Assignment. Finally, I explain the basis for my opinion that in the long run the treaty will benefit the United States economy.
\end{abstract}

\section{Introduction}

Scientific studies show that human beings cause global warming. Our voracity and endless craving eventually lead to a more vulnerable planet. Fortunately, we have just awoken from ignorance, searching for a way to better save this homeland. Consequently, "Green GDP", "Green Development" and other "green" initiatives have become popular. Because we share earth's environment, global environmental problems cannot be solved by one country. Instead, all the countries who are responsible for polluting the environment most act together to reduce overall pollution. Although signing an international treaty on global warming is a logical first step to combat global warming, the treaty could have some potential adverse consequences for the United States economy.

As a developed country, the U.S relies more on hightech industries. Therefore, the issue arises: whether an international treaty on global warming is good or bad for the United States economy?

Opinions are divided on this issue. Some people believe that the treaty will overall be good for American business, and ultimately lead to a strong economy. Others argue that the treaty will hurt the United States economy because reducing greenhouse gases emission will increase the cost of production, thereby making American products more expensive and placing them at a competitive disadvantage in the global marketplace. Critics also argue that those countries who do not sign this burden on developed nations under the principle of "common but differentiated responsibilities" (UNFC,1). The Kyoto Protocol has three main mechanisms: International Emissions Trading, Clean Development Mechanism (CDM), and Joint implementation (JI). treaty would share the benefit of environment protection without paying for it, thus raising moral issues and damaging the relationships among nations.

\section{Background}

\subsection{What is the treaty?}

The United Nations Framework Convention on Climate Change (UNFCCC) is an international treaty that establishes a framework for how specific international treaties ( "Kyoto Protocols" and "Paris Agreement") may be negotiated to set binding limits on greenhouse gas emissions.

\subsection{Kyoto Protocol}

Under the Kyoto Protocol, signatory nations agreed to binding emission reduction targets by controlling emissions of the main anthropogenic (i.e., human-emitted) greenhouse gases (GHGs) in ways that reflect underlying national differences in GHG emissions, wealth, and capacity to make the reductions (Grubb, M. ,2004).Recognizing that developed countries are principally responsible for the current high levels of GHG emissions in the atmosphere as a result of more than 150 years of industrial activity, the Protocol places a heavier

\subsection{The Paris Agreement}

The Paris Agreement sets out a global action plan to put the world on track to avoid dangerous climate change.

The Paris Agreement requires the signing nations to rapidly reduce their mission of greenhouse gases using the best available science to keep the increase in the average

\footnotetext{
* Corresponding author: 544914276@qq.com
} 
global temperature to well below $2^{\circ} \mathrm{C}$ above pre-industrial levels (European Commission, 1).And the INDC's require each individual country to make individual contributions in order to achieve the worldwide goal. Each nation must report their individual contributions every five years and are to be registered by the UNFCCC Secretariat. Countries can cooperate and pool their nationally determined contributions.

\section{The Opposing Views on the Paris Treaty}

\subsection{The Arguments in favor of the Treaty}

Advocates in favor of the treaty argue that the treaty will improve the United States economy because it requires participating nations to come up with ways to address global warming. The treaty uses a two-handed approach on the one hand, it requires the participants stop activities which would aggravate global warming. On the other hand, countries must also develop technology to better face global warming.

Pro-treaty advocates argue that limiting gas emissions will create a green economy. The rule in the treaty restricts maximum greenhouse gases emissions in every participating country, so the country has to limit its economic activities to meet this standard. This means more and more factories which aim at manufacturing will be closed, more coal-powered industries will be forbidden. The trend will be that the manufacturing-driven economy will change into a service industry-driven economy. On the other hand, the decrease in fossil fuel usage will certainly increase the potential of clean energy, including wind energy, water energy, tide energy and bioenergy. All these practices will not do harm to the nation's development, instead, it will promote the economy developing in a green manner.

According to pro-treaty advocates, this emission standard will propel new technology. A high gas emission industry can still exist as long as it complies with the rule. So if a heavy industry wants to survive, it must innovate. It can improve the performance of devices - increase the production efficiency-or come up with new high efficient and environment-friendly production modes. Both of these approaches will require new technology.

\subsection{The Argument against the Treaty}

Just as there are many people who support the Paris treaty, there are many others who oppose it. Anti- treaty advocates believe that there is no global warming problem and therefore argue that the Paris treaty is unnecessary. Some of the more radical scientists who share this believe are referred to by the derogatory term "deniers." Other individual scientists, institutions, and organizations believe there was a break or "hiatus" in the global warming theory.

Anti-treaty advocates point to the most reliable temperature data, from orbiting weather satellites, which show that there has been no warming for nearly two decades. Despite the constant barrage of hyperventilating headlines of a melting planet and the unceasing clamor of climate catastrophists and computer modelers, global temperatures have not been rising as predicted - except in the always-wrong computer models.

If opponents take the position that there is no such thing as "global warming", they claim that signing a global treaty concerning global warming is vain. There is still another part of opponents, who show their disagreement by emphasizing the damage brought by such an international treaty.

Former President George W.Bush rejected for two reasons. First, he believed that the costs of reducing greenhouse gases would impose disproportionate disbenefit on the American economy in pursuit of a stilluncertain benefit. Second, he disliked the treaty not binding poor or developing countries to curb emissions (Lee Lane, 2006).Bush thought the treaty was a Zero-Sum Game, and in this game, China would be the winner, while the U.S would be the loser.

The U.S. government's own research has confirmed that domestic programs to reduce greenhouse gas emissions would wreak havoc on the economy, sending jobs overseas to countries such as Mexico and China. The Argonne National Laboratory in the Department of Energy studied the economic effects of proposed greenhouse gas emissions cuts on six domestic industries (wood and allied products, steel, petroleum refining, aluminum, chemical manufacturing, and cement production) and found that they would be devastating. Numerous studies have shown that meeting any new treaty commitments would result in a dramatic decline in U.S. gross domestic product (GDP) (Trisko, 1997).

What is more, in 1992 the U.S. Department of Commerce released a study by DRI, Inc., the study found that job losses resulting from the treaty would average between 520,000 and 1.1 million per year, depending on whether the CO2 emission goal was 1990 levels or $10 \%$ below 1990 levels. More than 5 million additional jobs would be at risk due to these policies, with Texas, California, Pennsylvania, Ohio, Illinois and Michigan facing the greatest job losses (Trisko, 1997).

\section{My position}

After much research and thought, I have concluded the advantages of the international treaty on global warming outweigh its disadvantages. The purpose of the international treaty should be to solve while at the same time advance the overall economy in the end. Signing the international treaty would ensure that many countries will come together to protect the planet. As Obama says, "Paris Agreement is the best chance we have to save the one planet we have" (Elizabeth, 2015). Most importantly, it is a good way to contribute to the sustainable development which is always the core issue among the nations.

The treaty stimulates the environment-friendly business, benefiting a sustainable economy. As the emerging of sustainable development, the "green" company is standing out among his competitors. According to a UCLA-led study, companies that 
voluntarily adopt international 'green' practices and standards have employees who are 16 percent more productive than the average( Jon Simmons, 2015) .High productive employees make the company more energetic and competitive, and this kind of company is more attractive to customers since they also want to make green choices. In the United Kingdom, 54\% of consumers buy more environmentally friendly products compared to two years ago (Meglena, 2009). The international treaty is not merely a task among nations; the majority of the citizens want to play a part in reducing global warming.

Those who oppose the treaty claim that the global warming being on pause for two decades, and that the high cost of enforcement of the treaty making it not worth the candle are short-sighted. Although I admit that we should use the term "climate change" as opposed to "global warming" to describe the environmental devastation, we have to attach great importance on the environment degradation. It seems that we have spared our effort on something that not exactly exists, but the decreasing rainforests, rising sea level prove such efforts we make are necessity. We should put environment protection in the leading position when doing business for the good of the very people and future generations. As for the complaint that the treaty places uneven requirements on participating nations, I think it should no longer be a reason for the treaty's hurting American economy. Under the Paris Agreement, the INDCs mechanism will ensure that every country contributes its part in the context of its own national circumstances.

\section{Conclusion}

Global warming is a topic that we cannot ignore. As humans, we must maintain the delicate balance between the environment and the economy. The international treaty provides the tool we can use to achieve this goal. We need to protect the vulnerable environment, but also contribute to promote a strong economy.

However, people are divided on the effect on American economy that the international treaty has. Those who against the treaty claim that the high cost and unequal contribution brought by the treaty would harm the economy as a whole; some in favor of the treaty hold that the joint effort would totally create global cooperation.

I embrace the international treaty, because it will benefit the United States economy in the long run. To be honest, I was neutral when I first began to write this paper, believing that the treaty was a double-edge sword-it brought benefit, but also hurt the economy to some extent.
However, after researching the treaty, I changed my mind because my research shows that the treaty will be beneficial. Even if global warming is on pause as proved in some scientists' research, we should never gain economic growth at the expense of the environment degradation. Our ambition to cope with the climate change will eventually turn into an economic opportunity, shared by all the participants who fulfill their responsibility stipulated in the treaty. In the meantime, I highly recommend that the treaty be modified to enable all nations to participant voluntarily and without a compulsory provision. This will refuse the argument that the practice is a zero-sum game.

On my honor, I have neither received nor given unauthorized assistance in any manner on this paper.

\section{References}

1. Gillis, Justin. NYT,(2016).

2. Rhein, M.; Rintoul, S. R. IPCC WGI AR5 (Report). p. 257. (2013).

3. Battisti, David; Naylor, Rosamund L. Science 323, 5911(2009).

4. US National Research Council. Washington, D.C., U.S.A.: National Academy Press. p.3. (2001)

5. Grubb, M. 2(2004). International Review for Environmental Strategies 5 (1): 2 (PDF version).

6. http://unfccc.int/kyoto_protocol/items/2830.php

7. http://ec.europa.eu/clima/policies/international/nego tiations/paris/index_en.htm

8. William F. Jasper New American (08856540) Retrived from University Libraries database (2016).

9. Trisko, Eugene M., Burnett, H. Sterling. Retrived from Points of View Reference Center database (1997)..

10. http:/www.aei.org/wp-content/uploads/2014/07/strategic-options-for-the-bushadministration_160635893399.pdf

11. http://www.nbcnews.com/news/us-news/obamaclimate-deal-best-chance-we-have-save-one-planetn479026

12. http://www.monster.com/career-start/a/most-uniqueenvironmentally-friendly-benefits-at-greencompanies

13. http://www.theguardian.com/commentisfree/cifgreen/2009/nov/29/climate-change-europeancommission 